Trans

continentales
Transcontinentales

Sociétés, idéologies, système mondial

$2 \mid 2006$

Afrique plurielle

\title{
Le mouvement pour la démocratie en Chine
}

Jean-Philippe Béja, À la recherche d'une ombre chinoise. Le mouvement pour la démocratie en Chine (1919-2004), Paris, Le Seuil, coll. « L'Histoire immédiate », 2004, $262 \mathrm{p}$.

\section{Marie Holzman}

\section{OpenEdition}

\section{Journals}

Édition électronique

URL : http://journals.openedition.org/transcontinentales/1461

DOI : 10.4000/transcontinentales. 1461

ISBN : 978-2-8218-1408-0

ISSN : 1775-397X

Éditeur

Editions de la maison des sciences de l'homme

Édition imprimée

Date de publication : 30 juin 2006

Pagination : 178-180

ISBN : 2200-92169-1

ISSN : 1950-1684

Référence électronique

Marie Holzman, «Le mouvement pour la démocratie en Chine », Transcontinentales [En ligne], 2 | 2006, document 14, mis en ligne le 15 décembre 2012, consulté le 22 septembre 2020. URL : http://

journals.openedition.org/transcontinentales/1461; DOI : https://doi.org/10.4000/transcontinentales. 1461

Ce document a été généré automatiquement le 22 septembre 2020

Tous droits réservés 


\section{Le mouvement pour la démocratie en Chine}

Jean-Philippe Béja, À la recherche d'une ombre chinoise. Le mouvement pour la démocratie en Chine (1919-2004), Paris, Le Seuil, coll. «L'Histoire immédiate », 2004, $262 \mathrm{p}$.

\section{Marie Holzman}

\section{RÉFÉRENCE}

Jean-Philippe Béja

À la recherche d'une ombre chinoise. Le mouvement pour la démocratie en Chine (1919-2004),

Paris, Le Seuil, coll. «L’Histoire immédiate », 2004, 262 p.

1 Une des grandes questions qui se posent aux observateurs de la Chine et des pays de l'ancien bloc communiste est la suivante : comment se fait-il que le Parti communiste chinois (PCC) ait réussi à se maintenir au pouvoir après les chocs de l'effondrement de l'Union soviétique et de l'ouverture de la Chine à l'économie de marché ? Tout laissait supposer que le gouvernement chinois ne survivrait pas longtemps à la répression du mouvement démocratique de la place Tian'anmen en 1989, et que les années 1990 verraient une transition vers un système politique pluraliste, ou du moins une ébauche de réformes politiques. Il n'en fut rien. En 2006, le PCC, fort de ses quelque 70 millions de membres, continue à contrôler la Chine d'une main de fer, en maintenant une croissance économique qui frôle les 10 \% tous les ans, et sans céder une once de terrain à ses opposants, réels ou imaginaires. La réponse à ces questions semble implicite dans le titre (À la recherche d'une ombre chinoise) de l'essai de Jean-Philippe Béja, qui suit de près l'évolution du mouvement démocratique chinois depuis 1976. Si le mouvement pour la démocratie en Chine est resté aussi insaisissable qu'une ombre de 1919 à 2004, comment s'étonner de ses échecs successifs?

2 La thèse de l'auteur s'appuie sur un certain nombre de constats: depuis que les canonnières britanniques ont forcé l'Empire du Milieu à s'ouvrir au commerce mondial, 
en 1842, jamais les Chinois n'ont pu élire leurs dirigeants, ni jouir des libertés d'opinion, d'association, de publication garanties par une Constitution. Pourtant, dès le tournant du $\mathrm{Xx}^{\mathrm{e}}$ siècle, et surtout à partir de 1919, des voix se sont élevées pour réclamer l'instauration de la démocratie, le respect des droits de l'homme et la fin des dictatures. Même la venue au pouvoir du PCC n'a pas empêché ce courant de réapparaitre à de multiples occasions, notamment en 1957, durant le mouvement des Cent Fleurs, puis durant la révolution culturelle et en 1978, au moment où les réformes économiques se mettaient en place, en 1989 enfin, sur la place Tian'anmen, lorsque des millions de Chinois sont descendus dans la rue, dans tout le pays, pour réclamer plus de transparence, moins de corruption, et plus de liberté pour la presse.

3 Si ce mouvement reste voué à l'échec, c'est en partie grâce à l'efficacité de la répression qui, affirme l'auteur, parvient tout d'abord à repérer et à faire taire les éléments qui apparaissent comme particulièrement menaçants, puis à effacer de la mémoire de la population le souvenir même de la revendication. Jean-Philippe Béja observe comment les acteurs du mouvement démocratique doivent à chaque fois réinventer la formulation de leurs demandes. En effet, les écrits et les discours de leurs prédécesseurs ont été si efficacement gommés par le pouvoir que l'édifice du mouvement démocratique doit être repris à la base à chaque mouvement, c'est-à-dire pratiquement tous les dix ans. En 1989, par exemple, les étudiants qui saluaient la venue de Gorbatchev à Pékin et narguaient Deng Xiaoping ne connaissaient même pas le nom des dissidents du premier printemps de Pékin, jetés en prison depuis 1979. Aujourd'hui, les jeunes Chinois qui viennent poursuivre leurs études à l'étranger affirment avec aplomb qu'il ne s'est rien passé en Chine durant la nuit du 4 juin 1989, alors que plus d'un millier de leurs concitoyens ont trouvé la mort sous les roues des chars et par les fusils de l'armée.

4 Jean-Philippe Béja souligne également le rôle ambigu de l'intelligentsia chinoise, qui s'est toujours considérée comme le conseiller du prince plutôt que comme le défenseur des faibles. Pour lui, le pouvoir a réussi à acheter le silence des élites à coup d'avantages matériels divers : voyages à l'étranger, accès aux honneurs et aux postes universitaires, meilleurs salaires. Pourtant, depuis le début du xxi siècle, ces élites commencent à s'intéresser plus activement à ce qu'elles appellent "les plus démunis», et de nombreux avocats, médecins, étudiants s'efforcent, à leurs risques et périls, de relayer les protestations des victimes de la modernisation rapide du pays. Sans doute s'agit-il plus d'éviter des débordements trop violents que de s'attaquer de front à la démocratisation du système.

5 Même si le propos reste relativement pessimiste quant à la possibilité de voir le mouvement démocratique s'incarner enfin en force politique et laisse entendre que la démocratie, insaisissable depuis un siècle, risque de ne rester qu'une ombre, les succès économiques reléguant la réforme politique à un lointain avenir, la conclusion de l'ouvrage apporte une note d'espoir. Pour Jean-Philippe Béja, « on a l'impression que le régime post-totalitaire est en train d'évoluer vers un autoritarisme post-politique avec le soutien d'une grande partie des élites, y compris, pour la première fois depuis 1949 au moins, d'une grande partie de l'intelligentsia ». L'auteur se demande si la Chine va tenter de passer directement d'un régime totalitaire, dont la coquille continuerait d'exister, à une " gouvernance postmoderne sans passer par la démocratie ».

6 L'auteur, qui s'intéresse essentiellement aux années comprises entre 1989 et 2004, a choisi de ne pas analyser en détail la période républicaine, durant laquelle le 
mouvement démocratique a pu s'incarner au moins partiellement. De nombreux courants d'idées se sont alors exprimés librement et les communistes eux-mêmes ont dû, pour séduire la population des années 1940, affirmer leur foi en la démocratie. Même si ce discours était trompeur, il prouve que la population chinoise, elle, s'attendait à voir émerger un système démocratique réel et que cette possibilité est restée un stimulant récurrent pour des générations de penseurs et de militants. Peuton, dans ce cas, parler seulement d'une « ombre chinoise » ? Le débat reste ouvert !

\section{AUTEURS}

\section{MARIE HOLZMAN}

Auteur avec Bernard Debord de Wei Jingsheng, un Chinois inflexible, Paris, Éditions Bleu de Chine, 2005 